\title{
FUNARI, Pedro Paulo; PIÑON, Ana. A temática indígena na escola: subsídios para os professores. São Paulo: Editora Contexto, 2011.
}

\section{Aline Vieira de Carvalho}

Pesquisadora do NEPAM e coordenadora do Laboratório de Arqueologia Pública Paulo Duarte - NEPAM/Unicamp.

Contato: alinev81@gmail.com

\section{Victor Henrique da Silva Menezes}

Graduando em História pela Universidade Estadual de Campinas - e estagiário do Laboratório de Arqueologia Pública Paulo Duarte - NEPAM/Unicamp.

Contato: henrique.menezes92@gmail.com
${ }^{1}$ Para consultar o texto dos Parâmetros Curriculares Nacionais: http://portal.mec.gov. br/seb/arquivos/pdf/livro051.pdf
${ }^{2}$ Este número foi publicado pelo Programa Povos Indígenas no Brasil e está disponível no site: http:// pib.socioambiental.org/pt/c/0/1/2/ populacao-indigena-no-brasil. É preciso destacar, como o próprio Programa sinaliza, que este número que não reflete as diversidades internas de cada um dos grupos indígenas listados.
Porque seria necessário produzir um livro sobre a temática indígena em sala de aula no Brasil dos dias de hoje? Afinal, a partir dos Parâmetros Curriculares Nacionais ${ }^{1}$ discutimos exaustivamente em nossas escolas (e em nossos projetos pedagógicos) a questão da cidadania, da pluralidade do patrimônio sociocultural brasileiro, da luta contra qualquer forma de discriminação baseada em diferenças culturais (e também diferenças de classe social, de crenças, de sexo, de etnia ou outras características individuais e sociais), da pluralidade das memórias, entre outros temas onde, teoricamente, os grupos indígenas que compartilham o território que chamamos de Brasil estariam incluídos nos debates. Ou, mesmo nas Universidades, temas como o multiculturalismo, identidades fluidas e etnicidades estariam em constantes discussões resultando em pesquisas inovadoras sobre a temática indígena no Brasil. Como justificar a relevância de uma obra como essa? Esta é primeira questão que nos colocamos ao nos defrontar com o livro A temática indígena na escola: subsídios para os professores, publicado pela Editora Contexto (2011). A resposta, todavia, salta aos nossos olhos logo nas primeiras páginas.

A obra, arquitetada para ser lida e discutida por um amplo público, e, em especial, professores, destaca o papel ativo do Estado Nacional brasileiro no apagamento das memórias relacionados aos nativos americanos. O foco, entretanto, não fica no passado ou na instituição do Estado. Partindo da premissa de que a leitura do tempo passado é sempre realizada sobre o viés do presente, os autores destacam como as memórias sobre os indígenas são vivenciadas nos dias de hoje e são projetadas para o passado. Por mais surpreendente que possa ser, expressiva parcela dos jovens estudantes brasileiros continuam a perceber "o indígena" como o habitante das florestas distantes e pertencentes aos tempos longínquos (como utopias desencarnadas!). Nessas intuições, os indígenas não existem no presente e, quando existem, estão nas ocas da Amazônia (p. 109).

O completo desconhecimento dos 235 povos indígenas existentes no Brasil atual $^{2}$ dialoga com visões unipartidárias da nossa própria história. Dos conflitos e negociações entre esses nativos e os europeus que aqui chegaram 
ao último ano do século $\mathrm{XV}$, a memória que nos resta é sempre do indígena vencido ou desimportante! No geral, as pessoas não se percebem com possíveis antecessores indígenas e nem concebem as contribuições culturais importantíssimas da convivência destes diferentes grupos culturais: do universo da alimentação (da mandioca à batata, do tomate ao chocolate, algumas das contribuições americanas ao mundo), passando pelo universo dos próprios léxicos (Mogi, Caju, Pindamonhangaba, Anhanguera, entre tantos outros!) até a herança cultural do banho diário, os diálogos culturais entre os nativos e europeus são incomensuráveis e, constantemente, silenciados e esquecidos.

O livro, neste contexto, apresenta-se como fundamental ao Brasil dos dias de hoje. E sua inovação está na característica de mostrar, partindo de uma linguagem acessível e de conhecimentos produzidos em diversas ciências, que nenhum desses esquecimentos e memórias são naturais. Ou seja, o livro tem como premissa que os mecanismos de exclusão não são estáticos, atemporais ou simplesmente dados. Por não terem datas e locais de nascimento, essas artimanhas dos silenciamentos e das exclusões podem, portanto, serem alteradas.

Para a transformação, entretanto, é preciso ter conhecimento sobre esses poderes. O livro almeja suprir uma lacuna: oferecer uma visão plural e acessível sobre a constituição da temática indígena no Brasil. Para isso, os autores conceberam uma obra que se divide em quatro eixos temáticos ("As identidades", "Os índios", "A escola" e "A república"), e, em sua base, trabalha com a proposta de que não existem raças, mas apenas a raça humana.

Criticando, dessa forma, a contraposição entre "índios" e "brancos" como categoria de tipo racial, os autores iniciam o livro com a polêmica discussão acerca de quando se principia a História do Brasil. A história do continente americano tem sido narrada a partir de uma perspectiva européia, o que pode ser observado, por exemplo, quando é difundida a ideia de que a nossa história teria iniciado em 1500 com a chegada dos portugueses ou até mesmo em 1140 no momento de formação do Estado de Portugal. Tais abordagens na maioria das vezes acabam por excluir o fato de que bem antes de 1500 essas terras já haviam sido povoadas. Partindo desse pressuposto, Funari e Piñón inserem uma crítica quanto à forma que este tema é trabalhado dentro de uma sala de aula, onde alguns professores - ora devido à falta de informações nas escolas, ora às deficiências das políticas de valorização cultural em voga no país - "esquecem" de levar em consideração a (pré) e/ou história desses povos que aqui habitavam como um dos agentes que contribuem para a formação da história das terras que deram origem ao Brasil, influenciando indiretamente a ideia - presente em muitas pessoas, como mostra a pesquisa feita pelos autores e exposta no livro - de que a parte do continente que constituiria nosso país só passara a ser povoada com a chegada dos europeus.

Após essa breve discussão, nos capítulos que se sucedem, os autores trabalham com a explicação do significado de algumas denominações de povos indígenas, como por exemplo, Tupinambás (os descendestes do ancestral), Tupiniquins (o galho do ancestral), Tupi (ancestral), Guarani (guerreiro), Inca (senhor), entre outros. Discute-se a partir disso, o que é ser índio, combatendo ao mesmo tempo, a ideia de que todos aqueles que habitavam o continente antes de 1492 formavam um único povo. Funari e Piñón salientam que esses povos se autodenominavam "(...) de milhares de maneiras, cada povo a seu 
modo, com nomes que podiam significar simplesmente "seres humanos", por oposição a outros grupos" (p. 18), o que demonstraria as suas especificidades culturais.

Os autores tiveram também a preocupação em explicar alguns termos técnicos e conceitos que já foram utilizados, ou ainda são, nos estudos que versam sobre os povos indígenas, como "assimilação" (p.22), "aculturação" (p. 24), "modelo normativo" (p. 24), "etnogênese" (p. 26), "transculturação" (p. 26), "olhar antropológico" (p. 30), "desnaturalização" (p. 30), "abordagens culturalistas" (p. 44), "deculturação" (p. 72), "americanismos" (p. 95) e "invisibilidade do indígena" (p. 110). Essa estratégia de explicação de conceitos básicos nos estudos de determinados campos, tão presente nos demais trabalhos de Funari, mostrou-se completamente eficaz também nesta obra para uma melhor compreensão por parte do leitor de como o tema em questão deve ser estudado, além de auxiliar no entendimento das diferentes maneiras que o índio já foi apresentado a partir de conceitos tão fortes como estes; o que faz com que o leitor acompanhe as críticas relacionadas à abordagem da temática indígena que os autores constroem no decorrer da narrativa.

Há uma valorização das pesquisas arqueológicas, o que não poderia faltar em um livro escrito por arqueólogos que tem uma profunda preocupação em introduzir em seus trabalhos os estudos realizados com comunidades do passado e do presente através de sua cultura material. Pois, como enfatiza Funari e Piñón, "(...) a Arqueologia é outra grande fonte de informações sobre os índios e que, portanto, vale a pena ver o que descobriram e anotaram os arqueólogos" (p. 34), sendo que "(...) os vestígios arqueológicos podem mostrar como eram as aldeias indígenas, as ocas e a estrutura arquitetônica de importantes centros como as cidades maias ou as estradas incas, nos Andes, as melhores do mundo no século XV" (p. 37).

A trajetória do homem e povoação da América é trabalhada a partir das teorias difundidas pelas arqueólogas Maria Conceição Beltrão e Niède Guidon, e pelo biólogo Walter Neves. Em relação a visões antes consagradas, como a ideia de que nas sociedades caçadoras e coletoras havia necessariamente uma divisão de tarefas por sexo, ou seja, que o homem era o caçador e a mulher a que fazia a coleta e que, por isso, o homem seria hierarquicamente superior à mulher ( $p$. 46) é fortemente criticada pelos autores que trabalham com a ideia de que "(...) nem todas as sociedades indígenas eram (ou são) patriarcais" (p. 48). Partindo desse pressuposto, é sugerido no decorrer do livro que essas discussões sobre as mulheres sejam levadas à sala de aula, pois o tema do protagonismo social das mulheres, na nossa sociedade atual, é de grande importância. Assim, escrevem Funari e Piñón, caberia comentar sobre a diversidade de sexualidades registrada em tribos indígenas, onde pesquisas têm mostrado a existência de sociedades indígenas que reconheciam mais do que dois sexos (p.49).

Complementando a discussão sobre as relações de gênero dos povos indígenas que deveriam ser inseridas nas salas de aulas, os autores discutem e criticam a forma que a temática indígena foi tratada quando introduzida nos livros didáticos a partir de 1943, em que "(...) os índios eram quase sempre enfocados no passado e apareciam, muitas vezes, como coadjuvantes e não como sujeitos históricos, à sombra da atividade dos colonos europeus" (p. 97), e a "(...) colonização do continente americano pelos indígenas praticamente não era mencionada e os índios eram descritos por meio da negação de traços 
culturais considerados significativos, como falta de escrita, de governo e de tecnologia" (p. 98). Situação esta que só mudou a partir da segunda metade dos anos 1990 onde buscou-se a universalização da escola fundamental de oito anos e a valorização da diversidade cultural, o que resulta então na produção de novos materiais didáticos no qual passa a ser tratado com maior atenção temas indígenas, apresentando "(...) a povoação do continente como um tema em discussão pelos pesquisadores, com a apresentação de diversas teorias, o que favorece uma visão crítica sobre o conhecimento histórico por parte de estudantes" (p. 100).

Uma observação por parte dos autores que é importante destacar, é que, apesar da maior atenção dada nos livros didáticos e de novas políticas por parte do Ministério da Educação e das Secretarias Estaduais de Educação em relação à temática indígena, é perceptível que entre os estudantes ainda há uma profunda ignorância em relação ao tema. Tal afirmação provém a partir de uma pesquisa feita em escolas do Rio de Janeiro, Niterói, Campinas e Natal, dos sextos aos nonos anos do Ensino Fundamental, e que Funari e Piñón apresentam nos momentos finais do livro, no qual observa-se, por exemplo, que cerca de um terço dos entrevistados não souberam mencionar nenhuma tribo, que $73 \%$ consideram que os índios estão no Brasil desde 1500 e que quando questionados sobre a proveniência dos índios, que apenas $16 \%$ responderam que vieram da Ásia, única resposta que corresponde aquilo que está nos livros didáticos, que como explicam os autores, "(...) já deveriam ter sido incorporadas pela maioria dos estudantes, mas ainda não foi." (p. 108), o que demonstra avanços e limites das políticas educacionais dos últimos anos (p. 109).

Nos momentos finais do livro, os autores destacam que uma das maiores vitórias que a introdução na escola da temática indígena obteve foi fazer com que os estudantes passassem a se ver como descendentes de índios, algo que no passado não era visto no país, onde tentava-se apagar a nossa memória indígena, e que agora, "(...) o fato de que muitas crianças reconheçam ter parentes indígena mostra como a valorização do indígena, apesar de todos os problemas, avançou no nosso país" (p. 111); concluindo que "(...) a escola, por seu papel de formação da criança, adquire um potencial estratégico capaz de atuar para que os índios passem a ser considerados não apenas um "outro", a ser observado a distância e com medo, desprezo ou admiração, mas como parte deste nosso maior tesouro: a diversidade." (p. 116).

Uma obra inovadora, A temática indígena na escola: subsídios para os professores, constitui um riquíssimo trabalho de pesquisa e escrita por parte de Funari e Piñón e que é certo que terá grande aceitação entre os professores das redes públicas e privadas que há muito carecem de um trabalho como este, que é provável que lhes sirva de inspiração e auxílio para que repensem a forma como têm tratado a temática indígena na sala de aula ou até mesmo como eles têm colocado o índio na história quando está dando uma aula de História do Brasil ou da América. Para a próxima edição, sinaliza-se, todavia, a necessidade do maior cuidado editorial em relação às imagens: muitas não possuem legenda, créditos ou autoria.

Independente do cuidado editorial, podemos concluir que está é uma obra de grande relevância para o Brasil atual. E muito de sua relevância está em seu próprio engajamento. E, nestecaso, o engajamento não significa apenasolevantar de uma bandeira, mas, de forma complementar, como definiu a arqueóloga 
Solange Schiavetto, o engajamento é um "fazer científico inextricavelmente

${ }^{3}$ Schiavetto, Solange Nunes de Oliveira. "A questão étnica no discurso arqueológico: a afirmação de uma identidade indígena minoritária ou inserção na identidade nacional?" (p.85). In: Funari, PP.; Orser, C. Jr.; Schiavetto, S. N. de O. (orgs). Identidades, discurso e poder: estudos da arqueologia contemporânea. Annablume Fapesp. São Paulo, 2005. ligado à sociedade, agindo com e para ela" ${ }^{3}$. Assim, o engajamento do livro segue no sentido de contribuir com a construção de meios que permitam a reflexão autônoma, independente e consciente de professores, alunos, pais e interessados na temática. Reflexões que nos permitam compreender como "o Índio" foi se transformando em uma categoria essencializada, discriminada e silenciada ao longo de nossa história. 